\title{
Antibody-dependent macrophage-mediated cytotoxicity against Entamoeba histolytica
}

\author{
A. SAXENA, SHASHI CHUGH and V. K. VINAYAK* \\ Division of Experimental Parasitology and Parasitic Immunology, Department of Experimental Medicine, Post- \\ graduate Institute of Medical Education and Research, Chandigarh-160012, India
}

\begin{abstract}
Summary. Interactions between trophozoites of Entamoeba histolytica and peritoneal exudate macrophages from unsensitised and antigen-sensitised animals were studied in vitro. Normal macrophages killed trophozoites to some extent. This killing capacity was enhanced by prior sensitisation of the animals with specific antigen. Incorporation of anti-amoebic antiserum in the amoeba-macrophage mixture greatly enhanced the killing capacity of macrophages. Fraction one (F-I) of a crude amoebic extract was most effective in enhancing the cytotoxicity of macrophages by prior sensitisation and anti-F-I serum was the most effective antiserum. The cytotoxicity-inducing capacity of the immune serum resided in the IgG but not in the IgM fraction.
\end{abstract}

\section{Introduction}

Cellular immunity plays an important role in amoebic infections (Savanat et al., 1973; Ortiz-Ortiz et al., 1975; Harris and Bray, 1976; Jain et al., 1980; Vinayak et al., 1980), whereas humoral immune responses have little influence on the outcome of the disease (Vinayak et al., 1981). Although macrophages are important in host defence against various bacterial infections (Mackaness, 1962; Ruskin, et al., 1969; Behin et al., 1979), their role in amoebic infection has not been well documented. Recently, Ghadirian and Meerovitch (1982a, 1983) suggested that macrophages may be important in host defence against hepatic amoebiasis. We have already reported on the cytotoxic effect of lymphocytes against Entamoeba histolytica in association with anti-amoebic serum (Vinayak et al., 1984). Because macrophages also participate in antibody-dependent cellular cytotoxicity against various parasites (Capron et al., 1982), we studied the ability of macrophages to destroy $E$. histolytica in the absence or presence of anti-amoebic serum.

\section{Materials and methods}

\section{Trophozoites}

E. histolytica (NIH:200) was grown in TPS-I medium (Diamond, 1968) under axenic conditions.

Received 2 Apr. 1985; accepted 30 Aug. 1985.

* Correspondence and requests for offprints should be sent to V.K. Vinayak, Associate Professor, Department of Experimental Medicine, P.G.I.M.E.R., Chandigarh-160012, India.

\section{Antigens}

Crude amoebic extract (CAE) was prepared by sonicating washed trophozoites from 48 -h cultures for $5 \mathrm{~min}$ at $23 \mathrm{~K} \mathrm{~Hz}$ in the cold. Sonicated material was centrifuged at $10000 \mathrm{~g}$ for $30 \mathrm{~min}$ and the clear supernate labelled CAE.

\section{Fractionation of $C A E$}

CAE was fractionated as described by Sawhney et al. (1980). The highest mol.-wt fraction (F-I; mol-wt 650000 ) was used for further study.

\section{Immunisation}

Three- to four-week-old guinea pigs were immunised with CAE and F-I as described previously (Vinayak et al., 1984). Blood samples were collected on completion of the immunisation schedule just before killing the animals. The anti-amoebic antibody titres were determined by the method of Prakash et al. (1970).

\section{Peritoneal exudate macrophages}

Sixty ml of Iscove's MEM (Gibco, USA) were injected into the peritoneal cavities of guinea pigs. The abdomen of each animal was gently massaged and fluid withdrawn with a siliconised syringe. The peritoneal cells were harvested by centrifugation at $350 \mathrm{~g}$ for $10 \mathrm{~min}$ and resuspended in a small volume of MEM containing $10 \%$ normal heat-inactivated guinea pig serum. Cells $\left(5 \times 10^{5}\right)$ were seeded in each well of specially designed chambers prepared by fixing coverslips to one side of a hole $(1 \mathrm{~cm}$ diameter) in a microscope slide. The well was completely filled with the medium and sealed with another coverslip. The chambers were incubated in air plus $\mathrm{CO}_{2} 5 \%$ at $37^{\circ} \mathrm{C}$ for $1 \mathrm{~h}$. Non-adherent cells were removed by washing 
with MEM and the chambers re-incubated for $3 \mathrm{~h}$. The macrophages formed a monolayer on the lower coverslips.

\section{Cytotoxicity assays}

The cytotoxic potential of sensitised and unsensitised macrophages was studied by incubating trophozoites of E. histolytica with macrophages in a fixed ratio $(1: 50)$, with or without anti-amoebic serum (Anti-CAE or Anti$\mathrm{F}-\mathrm{I}$ ), for $4 \mathrm{~h}$ at $37^{\circ} \mathrm{C}$ in air plus $\mathrm{CO}_{2} 5 \%$. Trophozoites alone (with and without serum) were used as controls. After incubation the percentage of viable trophozoites was determined by a trypan blue dye exclusion method and phase-contrast microscopy (Guerrero et al., 1976); 20 microscope fields $(\times 20)$ were counted at random.

\section{Effect of 2-mercaptoethanol}

To determine the nature of the immunoglobulin involved in the cytotoxicity reaction, $50 \mu \mathrm{l}$ of $0.2 \mathrm{M} 2$ mercaptoethanol was mixed with $50 \mu \mathrm{l}$ of immune serum and added to the amoeba-macrophage mixture to give a final concentration of $0.03 \mathrm{M}$.

\section{Isolation of $\operatorname{IgG}$ and $\operatorname{Ig} M$}

IgM was isolated from anti-CAE and anti-F-I by chromatography on Sephadex G-200 (Lamon et al, 1975). The first half of the first fraction was pooled and the protein precipitated with $45 \%$ ammonium sulphate. The ammonium sulphate was removed with Sephadex G-25. IgG was isolated by DEAE-cellulose ion-exchange chromatography (Hudson and Hay, 1980), followed by ammonium sulphate precipitation. Both IgM and IgG were checked for purity and activity and their cytotoxicity-inducing capacity determined.

\section{Results}

\section{Cytotoxicity of macrophages}

The table shows that $23.9 \pm 2.5 \%$ of trophozoites were killed by unstimulated macrophages. Stimulation of macrophages in vivo with specific antigens resulted in enhanced killing capacity. CAE-stimulated macrophages killed $40 \cdot 37 \pm 2 \cdot 0 \%$ amoebae and F-I-stimulated macrophages killed $61 \cdot 0 \pm 3 \cdot 5 \%$ amoebae (table). The cytotoxic potential of macrophages was significantly enhanced when anti-amoebic antiserum was added to the amoeba-macrophage mixture. Almost all trophozoites $(99.08 \pm 1.82 \%)$ were killed by the combination of unstimulated macrophages and anti-F-I serum. Similarly, F-I stimulated macrophages killed $100 \pm 1.5 \%$ of amoebae in the presence of anti-F-I serum (table). Inactivation of antiserum did not
Table. Killing of trophozoites by unstimulated and antigen-stimulated macrophages in the absence or presence of anti-amoebic serum

\begin{tabular}{c|ccc} 
& \multicolumn{3}{|c}{$\begin{array}{c}\text { Percentage }( \pm \text { s.d.) of trophozoites killed } \\
\text { in the presence of }\end{array}$} \\
\cline { 2 - 4 } Effector cells & NGPS & Anti-CAE serum Anti-F-I serum & Anced \\
\hline $\begin{array}{c}\text { Unstimulated } \\
\text { macrophages }\end{array}$ & $23.9 \pm 2.5$ & $46.33 \pm 1 \cdot 10$ & $99.08 \pm 1.82$ \\
$\begin{array}{c}\text { CAE-stimulated } \\
\text { macrophages }\end{array}$ & $40.37 \pm 2.0$ & $70 \cdot 12 \pm 1.25$ & N.D. \\
$\begin{array}{c}\text { F-I-stimulated } \\
\text { macrophages }\end{array}$ & $61.0 \pm 3.5$ & N.D. & $100 \pm 1.5$ \\
\hline
\end{tabular}

N.D. $=$ Not Done.

NGPS $=$ Normal Guinea Pig Serum .

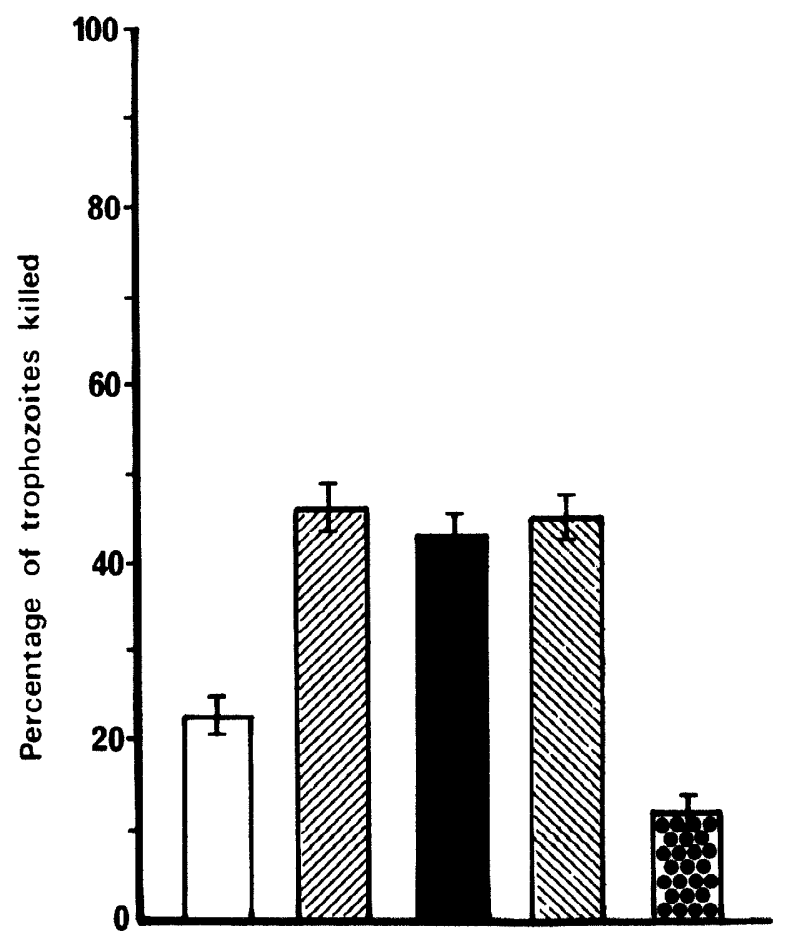

Fig. 1. Capacity of isolated immunoglobulins from anti-CAE to induce cytotoxicity by peritoneal exudate macrophages: normal guinea-pig serum ( $(\square)$, anti-CAE (区), 2-mercaptoethanol-treated

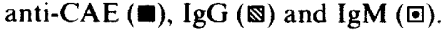

alter the ability of anti-amoebic serum to induce cytotoxicity of macrophages.

\section{Nature of antibodies}

2-Mercaptoethanol had no effect on the capacity of anti-amoebic serum to induce cytotoxicity (figs 1 


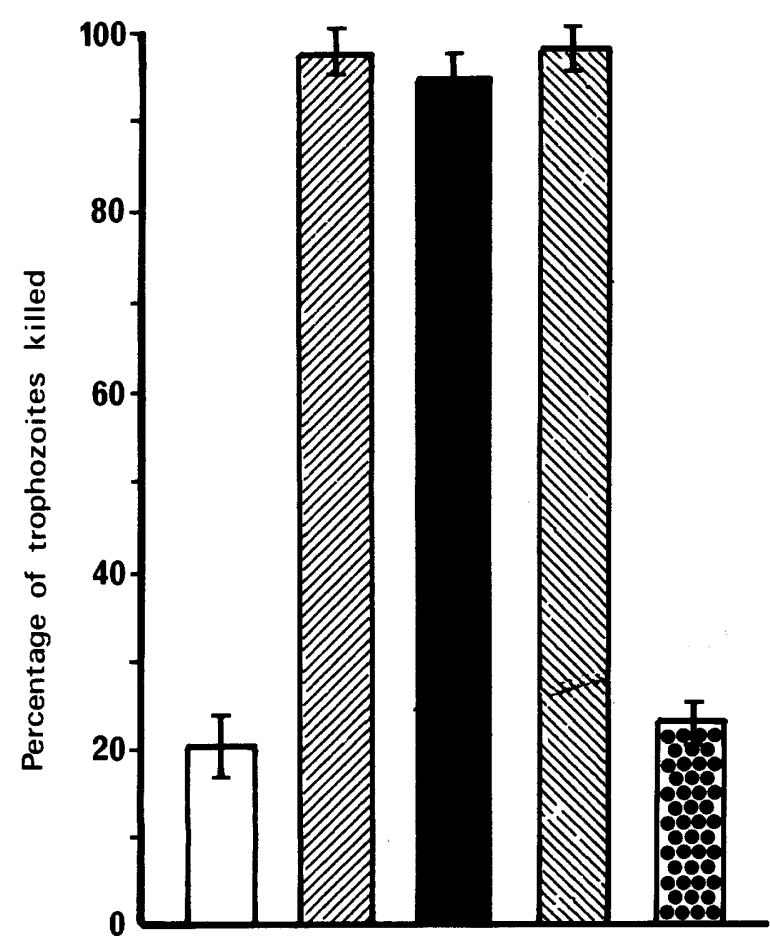

Fig. 2. Capacity of isolated immunoglobulins from anti-F-I to induce cytotoxicity by peritoneal exudate macrophages: NGPS ( $\square$ ), anti-F-I (四), 2-mercaptoethanol-treated anti-FI (ם), $\operatorname{IgG}(\mathbb{Q})$ and $\operatorname{IgM}(\mathbb{0})$.

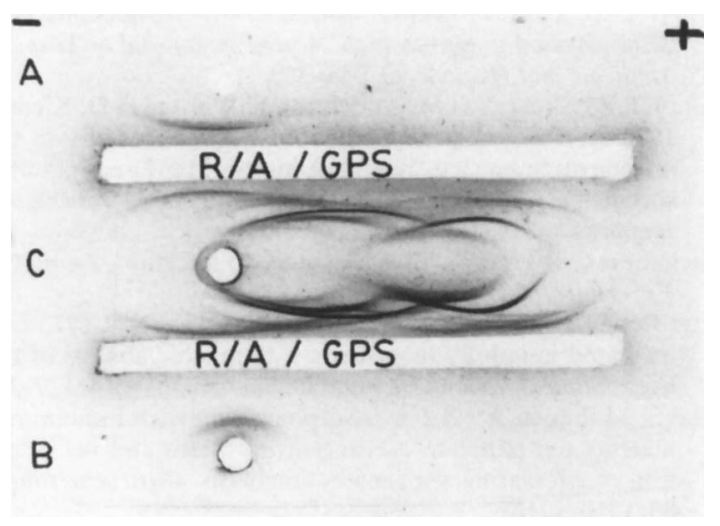

Fig. 3. Immunoelectrophoresis of isolated IgG and IgM from anti-CAE against R/A/GPS. (A) IgG, (B) IgM, (C) NGPS.

and 2). Reasonably pure IgG and IgM was isolated from anti-CAE and anti-F-I (fig. 3). The ability of anti-amoebic serum to induce cytotoxicity was contained in the IgG fraction; killing in the presence of IgG was similar to that in the presence of whole serum $(44.77 \pm 1.27 \%$ for IgG anti-CAE and $99.62 \pm 0.76 \%$ for IgG anti-F-I). Figs 1 and 2 show

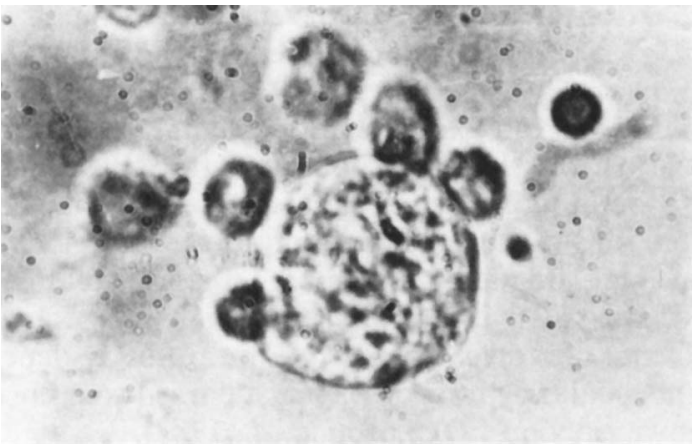

Fig. 4. Interaction between macrophages and E. histolytica in the presence of anti-F-I. Many macrophages can be seen attached to the trophozoite $(\times 1500)$.

that IgM did not induce cytotoxicity of macrophages.

Physical contact between macrophages and trophozoites was required to induce killing by the former (fig. 4) and more than one macrophage attached to a trophozoite in the presence of anti-F-I serum.

\section{Discussion}

High levels of anti-amoebic antibodies have been reported in cases of hepatic amoebiasis (Kessel et al., 1965; Prakash et al., 1970; Vinayak, 1975). However, anti-amoebic antibody titres showed little or no correlation either with virulence indices or with severity of the disease (Vinayak et al., 1981) indicating that humoral immunity alone had little or no role to play. On the other hand, cellular immunity is depressed during amoebic infection (Ortiz-Ortiz et al., 1975; Jain et al., 1980) and experimental immunosuppression with steroids and anti-lymphocytic serum resulted in more severe lesions in animals (Vinayak et al., 1982). Because a high degree of protection is achieved by immunisation with partially purified antigens (Krupp, 1974; Vinayak. et al., 1980), and vaccination not only augments antibody production but also primes the effectors of cellular immunity, there may be an association between the two arms of the host defence system. We found that unstimulated macrophages killed amoebic trophozoites in vitro. The killing capacity of the resident macrophages was greatly enhanced by antigen sensitisation or by addition of anti-amoebic serum. The F-I fraction of $\mathrm{CAE}$ was the most effective inducer of macrophage cytotoxicity by prior sensitisation and by anti-F-I serum. This in-vitro cytotoxic potential correlated well with protection studies with F-I (Krupp, 1974; Vinayak et al., 1980). 
Peritoneal exudate cells of vaccinated animals are not phagocytosed by amoebae but kill them (Ghadirian and Meerovitch, 1982b). Similar result were obtained in our experimental system. However, we have shown that macrophage cytotoxicity could also be induced by anti-amoebic serum. Furthermore, this capacity of the immune serum resided in the IgG fraction-2-mercaptoethanol treatment did not alter it and purified IgG was equally effective. Involvement of IgG in antibody-dependent cellular cytotoxicity against parasites has been shown previously (Capron et al., 1982).

The existence of $\mathrm{Fc}$ receptors of $\mathrm{IgG}$ on macrophages has been well documented (Unanue, 1981). It is conceivable that the IgG of an immune serum binds to the surface of the trophozoite by its Fab portion and to the macrophage by its Fc portion, thus signalling the macrophage to kill the trophozoite. It seems that attachment of macrophages to the trophozoite is necessary to induce cytotoxicity. It was observed that in the presence of anti-F-I serum a large number of macrophages attached to trophozoites, often completely surrounding them,

\section{REFERENCES}

Behin R. Mauel J, Sordat B 1979 Leishmania tropica: pathogenicity and in vitro macrophage function in strains of inbred mice. Experimental Parasitology 48:81 91.

Capron A. Dessaint J P. Haque A, Capron M 1982 Antibody dependent cell mediated cytotoxicity against parasites. Progress in Allergy 31:234-267.

Diamond L S 1968 Techniques of axenic cultivation of Entamoeha histolytica Schaudinn, 1903 and E. histolytica-like amebae. Journal of Parasitology 54:1047-1056.

Ghadirian E, Meerovitch E. $1982 a$ Macrophage requirement for host defence against experimental hepatic amoebiasis in the hamster. Parasite Immunology 4:219-225.

Ghadirian E. Meerovitch E $1982 b$ In vitro amoebicidal activity of immune cells. Infection and Immunity 36:243 246 .

Ghadirian E. Meerovitch E. Kongshavn PAL 1983 Role of macrophages in host defense against hepatic amoebiasis in hamsters. Infection and Immunity 42:1017-1019.

Guerrero M, Rios D, Landa L 1976 Interactions between trophozoites of Entamoeba histolytica and lymphocytes of patients with invasive amoebiasis. In: Proceedings of an international conference on amoebiasis. Mexico City. 1975. p 529.539

Harris W G, Bray R S 1976 Cellular sensitivity in amoebiasisPreliminary results of lymphocytic transformation in response 10 specific antigen and to mitogen in carrier and disease states. Transactions of Royal Society of Tropical Medicine and Hygiene 70:340 343.

Hudson L, Hay F C 1980 Practical Immunology, 2nd edn. Blackwell Scientific, Oxford, p 169.

Jain P. Sawhney S. Vinayak V K 1980 Experimental amoebic infection in guinea-pigs immunized with low grade amoebic infection. Transaction of Roval Society of Tropical Medicine and Higiene 74:347 350 and that the absolute number of trophozoites (dead and alive) was significantly decreased $(p<0.001)$ after incubation for $4 \mathrm{~h}$ with macrophages in the presence of anti-F-I serum. Trophozoites were disintegrated, sometimes beyond recognition, by macrophages and it is thought that macrophages break down trophozoites before engulfing them.

We believe that specific anti-F-I antibodies may be important, in association with effector cells of the immune system, in combating invading trophozoites of $E$. histolytica. Specific cell-mediated immune responses are depressed after amoebic infection (Jain et al., 1980) and it is probable that a deficiency in one arm of the immune system is responsible for the effectiveness of E. histolytica as a parasite.

It has been shown that patients with hepatic amoebiasis have circulating immune complexes in their serum (Pillai and Mohimen, 1982). These may bind to the $\mathrm{Fc}$ receptors on the macrophages, rendering them unavailable for binding to IgG of immune serum. This is being studied in our laboratory.

Kessel J F. Lewis W P. Pasquel C M, Turner J A 1965 Indirect hemagglutination and complement fixation tests in amebiasis. American Journal of Tropical Medicine and Hygiene 14: $540-550$

Krupp I M 1974 Protective immunity to amebic infection demonstrated in guinea pigs. American Journal of Tropical Medicine and Hygiene 23:355-360.

Lamon E W, Skurzak H M, Andersson B, Whitten H D, Klein E 1975 Antibody-dependent lymphocyte cytotoxicity in the murine sarcoma virus system: Activity of IgM and IgG with specificity for MLV determined antigen(s). Journal of Immunology 114:1171-1176.

Mackaness G B 1962 Cellular resistance to infection. Journal of Experimental Medicine 116:381-406.

Ortiz-Ortiz L, Zamacona G, Sepulveda B, Capin N R 1975 Cell mediated immunity in patients with amebic abscess of the liver. Clinical Immunology and Immunopathology 4: 127-34.

Pillai S, Mohimen A 1982 A solid phase sandwich radioimmunoassay for Entamoeba histolytica proteins and the detection of circulating antigens in amebiasis. Gastroemerology 83: $1210-1216$.

Prakash O, Sama S K, Vinayak V.K, Bhalla I 1970 Evaluation of a new antigen for haemagglutination tests in amoebiasis. American Journal of Tropical Medicine and Hygiene 19:418421

Ruskin J, McIntosh J, Remington J S 1969 Studies on the mechanisms of resistance to phylogenetically diverse intracellular organisms. Journal of Immunology 103:252 256.

Savanat T, Viriyanond P, Nimitmongkol N 1973 Blast transformation of lymphocytes in amebiasis. American Journal of Tropical Medicine and Hygiene 22:705-710.

Sawhney S, Chakravarti R N, Jain P, Vinayak V K 1980 Immunogenicity of axenic Entamoeba histolytica antigen and its fractions. Transactions of Royal Society of Tropical Medicine and Hygiene 74:26-29. 
Unanue E R 1981 The regulatory role of macrophages in antigenic stimulation. II. Symbiotic relationship between lymphocytes and macrophages. Advances in Immunology 31:1-136.

Vinayak V K 1975 The specificity of the indirect haemagglutination test in the immunodiagnosis of amoebiasis. Indian Journal of Preventive and Social Medicine 6:271-276.

Vinayak V K, Jain P, Gupta B, Kaushik S P, Sawhney S 1980 Cellular and humoral responses in amoebic patients. Tropical and Geographical Medicine 32:298-302.

Vinayak V K, Sawhney S, Jain P, Chugh S, Naik S R,
Chakravarti R N 1981 Virulence of Entamoeba histolytica in rat and its comparison with the serological responses of the amoebic patients. Transactions of Royal Society of Tropical Medicine and Hygiene 75:32-37.

Vinayak V K, Sawhney S, Jain P, Chugh S, Chakravarti R N 1982 Immunosuppression and experimental amoebiasis in guinea-pigs. Annals of Tropical Medicine and Parasitology 76:309-316

Vinayak V K, Chugh S, Saxena A, Sharma S P 1984 Antibodydependent lymphocyte mediated cytotoxicity in amoebiasis. Indian Journal of Medical Research 80:421-427. 